\title{
Effects of alkanolamide addition on cure characteristics, crosslink density and tensile properties of carbon-black-filled styrene-butadiene rubber compounds
}

\author{
Indra Surya ${ }^{1,2, *}$, and Hanafi Ismail $^{3}$ \\ ${ }^{1}$ Universitas Sumatera Utara, Department of Chemical Engineering, Medan, 20155, Indonesia \\ ${ }^{2}$ Universitas Sumatera Utara, Sustainable Energy and Biomaterial Center of Excellence, Faculty of Engineering, Medan, 20155, \\ Indonesia \\ ${ }^{3}$ Universiti Sains Malaysia, School of Materials and Mineral Resources Engineering, Engineering Campus, 14300, Nibong Tebal, \\ Penang, Malaysia
}

\begin{abstract}
By using a semi-efficient sulphur vulcanisation system, the effects of alkanolamide (ALK) addition on cure characteristics, crosslink density and tensile properties of carbon black (CB)-filled styrenebutadiene rubber (SBR) compounds were investigated. The ALK was prepared from Refined Bleached Deodorized Palm Stearin and diethanolamine and added into the CB-filled SBR compounds. The ALK loadings were 1.0, 3.0, 5.0 and $7.0 \mathrm{phr}$. It was found that ALK decreased the scorch and cure times of the CB-filled SBR compounds. ALK also improved the tensile modulus and tensile strength; especially up to a $5.0 \mathrm{phr}$ of loading. The crosslink density measurement proved that the $5.0 \mathrm{phr}$ of ALK exhibited the highest degree of crosslink density which caused the highest in tensile modulus and tensile strength. Due to its plasticity effect, ALK increased the elongation at break of the CB-filled SBR vulcanisates.
\end{abstract}

\section{Introduction}

The rubber formulations are supposed as the heart of rubber compounding, which contains various rubbers and rubber additives and their suitable amounts [1]. The base rubber will provide rubbery behavior to the compound; rubber additives such as fillers reinforce the rubbers or can cheapen the cost of rubber products; plasticisers are used to decrease viscosity, improve deformability and change properties; and accelerators are something that enhance the sulphur reaction [1].

Rubber additives are categorized into curative and non curative additives. Curative additives influence the cure characteristics of rubber compounds and noncurative additives do not. A number of investigations on curative additives have reported by some researchers. Barton and Hart [2] reported that modulus values have enhanced as the lauric acid content increases. Coran [34] has studied on the concentration effect of stearic acid on natural rubber (NR). He found that the stearic acid causes retardation in cure where, the specific rate of sulphur reaction decreased if the concentration of stearic acid was enhanced. Poh and Tang [5] reported that the scorch time increases with the stearic acid content for all the rubbers they investigated.

Ismail et al. [6-9] have introduced a commercially diamine salt of fatty acid of general molecular structure $\left[\mathrm{RNH}_{2}{ }^{+} \quad\left(\mathrm{CH}_{2}\right)_{3} \mathrm{NH}_{3}{ }^{+}\right]\left[\mathrm{R}^{\prime} \mathrm{COO}-\right]_{2}, \quad$ referred to a multifunctional additive (MFA). The additive could function as an accelerator and internal plasticiser which improved the carbon black (CB) in NR compounds. The existence of MFA is also a promising since this additive offers efficiency in rubber mixing process.

Ismail and Ruhaizat [9-10] have introduced Palm Oil Fatty Acid (POFA) as a curative additive in rubber compounds. The additive based on the fatty acids of palm oil. They reported that the concentration of POFA affects both the curing characteristics and mechanical properties of the unfilled and calcium carbonate filled NR compounds.

Through vulcanisation, the weak and plastic raw rubber is converted into strong elastic rubber vulcanisate. The strength and elasticity can be further enhanced by the addition of a reinforcing filler into the rubber compounds. The $\mathrm{CB}$ and silica are the most popular reinforcing fillers in rubber industry and they are used to reinforce the rubber compounds. Due to their fine particles, at a relatively higher filler loading, their filler particles tend to agglomerate and it can deteriorate the properties of the rubber products. Practically, to solve the filler dispersion problem, special additives such as processing aid, dispersant aid are used.

Based on the above reality, alkanolamide (ALK) was used to solve filler dispersion problem. Therefore, this study reports the utilization of ALK in CB reinforcement of styrene-butadiene rubber (SBR) compounds. The effects of ALK addition on cure characteristics, crosslink density and tensile properties of SBR compounds were reported.

\footnotetext{
Corresponding author: indradanas@yahoo.com
} 


\section{Experimental}

\subsection{Materials}

Styrene-butadiene rubber (SBR), Taipol 1502, was purchased from TSRC Corporation, Taiwan. An N330grade CB was supplied by the Cabot Corporation. Other compounding ingredients, such as sulphur, zinc oxide, stearic acid, $\mathrm{N}$ isopropyl-N'-phenyl-p-phenylenediamine (IPPD), and benzothiazolyl disulfide (MBTS), were supplied by Bayer Co. (M) Sdn. Bhd., Petaling Jaya, Selangor, Malaysia. All materials were utilised as supllied. The ALK was prepared using RBDPS and diethanolamine. The procedure of the ALK preparation was given in our previous report [11-15] and its chemical formula is $\mathrm{CH}_{3}\left(\mathrm{CH}_{2}\right)_{14} \mathrm{CON}\left(\mathrm{CH}_{2} \mathrm{CH}_{2} \mathrm{OH}\right)_{2}$.

\subsection{Compounding}

A semi effisient sulphur-accelerated vulcanisation system was used for compounding. The recipe for the preparation of the CB-filled SBR compounds is given in Table 1. The compounding procedure was done in accordance with the American Society for Testing and Material (ASTM) - Designation D 3184 - 80. Compounding was done on a two-roll mill.

Table 1. The composition of the SBR compounds.

\begin{tabular}{|l|l|}
\hline Ingredients & ${\text { Content }(\mathrm{phr})^{\mathrm{a}}}^{\mathrm{a}}$ \\
\hline SBR & 100.0 \\
\hline ZnO & 5.0 \\
\hline Stearic acid & 2.0 \\
\hline IPPD & 2.0 \\
\hline MBTS & 1.5 \\
\hline Sulphur & 1.5 \\
\hline CB N330 & 30.0 \\
\hline ALK & $0.0 ; 1.0 ; 3.0 ; 5.0 ; 7.0$ \\
\hline
\end{tabular}

\subsection{Cure characteristics}

The cure characteristics of the CB-filled SBR compounds were obtained using a Monsanto Moving Die Rheometer (MDR 2000) which was employed to determine the scorch time $\left(\mathrm{ts}_{2}\right)$, cure time $\left(\mathrm{t}_{90}\right)$, minima torque $\left(\mathrm{M}_{\mathrm{L}}\right)$ and maxima torque $\left(\mathrm{M}_{\mathrm{H}}\right)$ were measured according to ASTM D2084. Samples of the respective rubber compounds were tested at $150{ }^{\circ} \mathrm{C}$. The $\mathrm{CB}$-filled SBR compounds were subsequently compression moulded using a stainless steel mould at $150^{\circ} \mathrm{C}$, with a pressure of $10 \mathrm{MPa}$ and applying a laboratory hot-press based on respective curing times.

\subsection{Measurement of crosslink density}

Swelling tests on the SBR vulcanisates were performed in toluene in accordance with ISO 1817. The cured test pieces $(30 \mathrm{~mm} \times 5 \mathrm{~mm} \times 2 \mathrm{~mm})$ were weighed using an electrical balance and swollen in toluene until equilibrium, which took 72 hours at room temperature. The samples were taken out from the liquid, the toluene was removed from the sample surfaces and the weight was determined. The samples were then dried in the oven at $60{ }^{\circ} \mathrm{C}$ until constant weights were obtained. The swelling results were used to calculate the molecular weight between two crosslinks $\left(M_{c}\right)$ by applying the Flory-Rehner Equation [16-17].

$$
\begin{gathered}
M_{c}=\frac{-\rho_{p} V_{s} V_{r}^{1 / 3}}{\ln \left(1-V_{r}\right)+V_{r}+\chi V_{r}^{2}} \\
V_{r}=\frac{1}{1+Q_{m}}
\end{gathered}
$$

Where $\rho$ is the rubber density $(\rho$ of SBR $=0.94$ $\left.\mathrm{g} / \mathrm{cm}^{3}\right), V_{s}$ is the molar volume of the toluene $\left(V_{s}=106.4\right.$ $\left.\mathrm{cm}^{3} / \mathrm{mol}\right), V_{r}$ is the volume fraction of the polymer in the swollen specimen, $Q_{m}$ is the weight increase of the blends in toluene and $\chi$ is the interaction parameter of the rubber network-solvent $(\chi$ of SBR $=0.49)$. The degree of the crosslink density is given by;

$$
V_{c}=\frac{1}{2 M_{c}}
$$

\subsection{Tensile properties}

Dumbbell-shaped samples were cut from the moulded sheets. Tensile tests were performed at a cross-head speed of $500 \mathrm{~mm} / \mathrm{min}$ using an Instron 3366 universal tensile machine according to ISO 37. The tensile strength (TS), stress at 100\% elongation (M100), 300\% elongation (M300) and elongation at break (EB) were investigated.

\section{Results and discussion}

\subsection{The cure characteristics}

The effects of ALK addition on the scorch and cure times of CB-filled SBR compounds are shown in Table 2. As shown, a $1.0 \mathrm{phr}$ addition of ALK decreased the scorch and cure times. A cure enhancement was observed and in this case, ALK was considered as cocuring agent. It was due to the amine part of ALK which contributed to the cure enhancement [11,13, 15, 18-19]. It was also seen that the higher the ALK loading, the lower were the scorch and cure times. It was simply due to a more content of amine was present in the CB-filled SBR compounds.

Table 2 also shows the torque properties of the CBfilled SBR compounds. The additions of ALK up to 5.0 phr increased torque difference $\left(\mathrm{M}_{\mathrm{H}}-\mathrm{M}_{\mathrm{L}}\right)$ value and decreased beyond the loading. 
Table 2. Cure characteristics of CB-filled SBR compounds at various ALK loadings.

\begin{tabular}{|c|c|c|c|c|c|}
\hline \multirow{2}{*}{ Cure characteristics } & \multicolumn{5}{|c|}{ ALK loadings (phr) } \\
\hline & 0.0 (Control) & 1.0 & 3.0 & 5.0 & 7.0 \\
\hline ts 2 , min. & 5.07 & 4.03 & 2.89 & 2.23 & 2.09 \\
\hline $\mathrm{t}_{90}, \mathrm{~min}$. & 12.76 & 11.15 & 8.15 & 6.85 & 6.13 \\
\hline $\mathrm{M}_{\mathrm{H}}, \mathrm{dN} . \mathrm{m}$ & 10.11 & 11.90 & 12.47 & 12.96 & 11.99 \\
\hline $\mathrm{M}_{\mathrm{L}}, \mathrm{dN} \cdot \mathrm{m}$ & 1.29 & 1.27 & 1.23 & 1.21 & 1.08 \\
\hline $\mathrm{M}_{\mathrm{H}}-\mathrm{M}_{\mathrm{L}}, \mathrm{dN} \cdot \mathrm{m}$ & 8.82 & 10.63 & 11.24 & 11.75 & 10.91 \\
\hline
\end{tabular}

The torque difference indicates degree of crosslink density of a rubber compound [9, 20-22]. A greater torque difference means a higher degree of crosslink density.

The decrease of the torque difference beyond $5.0 \mathrm{phr}$ was due to the dilution effect of the excessive amount of ALK which most probably not only absorbed CB filler and part of curatives but also decreased the total crosslink density.

\subsection{The crosslink density}

Fig. 1 shows the effect of ALK loading on crosslink density of CB-filled SBR vulcanisates. As shown, the addition of $1.0 \mathrm{phr}$ of ALK increased the crosslink density of CB-filled SBR compound significantly. Increases the ALK loading up to a $5.0 \mathrm{phr}$ caused a further increase in crosslink density. Beyond the loading started to decrease the crosslink density.

The increases in crosslink density were due to the additional function of ALK as an internal plasticiser agent $[11-12,15]$ which plasticized, softened and decreased the viscosity of the filled SBR compounds. A lower viscosity tent to make easier the filler dispersion and enhanced rubber-filler interaction, respectively. The SBR-CB filler interaction can be defined as additional physical crosslinks [23-24] and, together with sulphide crosslinks, contributed to total crosslink density [25-26].

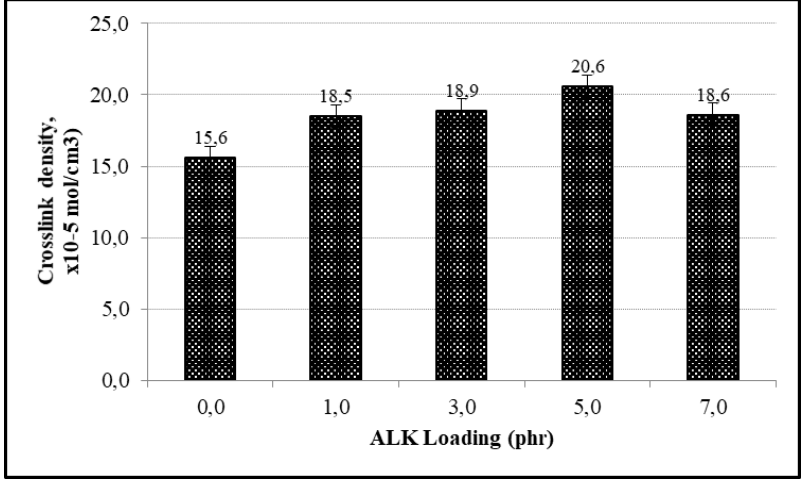

Fig. 1. The effect of ALK loading on crosslink density of CBfilled SBR vulcanisates.

\subsection{The tensile properties}

Table 3 shows the effects of ALK addition on the M100, M300, TS and EB of CB-filled SBR vulcanisates. The ALK additions up to $5.0 \mathrm{phr}$ increased M100, M300 and TS; beyond the loading decreased those properties.

The M100, M300 and TS depend on the degree of crosslink density $[9,27]$. The increases of those properties up to the optimum loading ( $5 \mathrm{phr}$ ) were was due to a higher degree of crosslink density. The decrease of those properties beyond the optimum loading was due to a lower degree of crosslink density. This explanation is in line with the crosslink density and torque difference results in Table 2 and Fig. 1.

Table 3. The tensile properties of CB-filled SBR vulcanisates at various ALK loadings.

\begin{tabular}{|l|r|r|r|r|r|}
\hline \multirow{2}{*}{ CB-filled SBR vulcanisates } & \multicolumn{5}{|c|}{ ALK Loadings (phr) } \\
\cline { 2 - 6 } & \multicolumn{1}{|c|}{0 (Control) } & \multicolumn{1}{c|}{1.0} & \multicolumn{1}{c|}{3.0} & \multicolumn{1}{c|}{5.0} & \multicolumn{1}{c|}{7.0} \\
\hline M100, MPa & $1.31 \pm 0.09$ & $1.34 \pm 0.09$ & $1.39 \pm 0.12$ & $1.43 \pm 0.10$ & $1.35 \pm 0.09$ \\
\hline M300, MPa & $3.18 \pm 0.06$ & $3.89 \pm 0.07$ & $4.47 \pm 0.08$ & $4.73 \pm 0.08$ & $3.58 \pm 0.09$ \\
\hline EB, \% & $770.9 \pm 17.5$ & $776.1 \pm 18.9$ & $782.1 \pm 19.8$ & $829.2 \pm 19.2$ & $866.7 \pm 20.2$ \\
\hline TS, MPa & $18.2 \pm 0.5$ & $18.8 \pm 0.5$ & $19.1 \pm 0.6$ & $19.8 \pm 0.6$ & $18.1 \pm 0.8$ \\
\hline
\end{tabular}

The effects of ALK addition on EB of the CB-filled SBR vulcanisates are also shown in Table 3. As shown, the ALK increased the EB of the CB-filled SBR vulcanisates. The EB increases with increasing the ALK loadings. Again, it was due to the function of ALK as an additional plasticiser which modified the flexibility of CB-filled SBR vulcanisates. The ALK provided free volumes which allowed a more flexibility for the rubber chains to move. The higher the ALK loading, the greater were the free volumes and the more flexible were the rubber chains. Presumably, the free volumes were in the layers of excessive ALK [9].

\section{Conclusions}

From this study, the following conclusions were drawn:

- Alkanolamide was a co-curing agent which increased the cure rate of carbon black-filled styrene-butadiene rubber compounds.

- Alkanolamide increased the degree of crosslink density and tensile properties of carbon black-filled styrene-butadiene rubber compounds especially up to $5.0 \mathrm{phr}$. 
- A $5.0 \mathrm{phr}$ loading of alkanolamide was the optimum loading for carbon black-filled styrenebutadiene rubber compounds.

The authors would like to thank Universiti Sains Malaysia for providing the research facilities for carrying out the experiment and for making this research work possible.

\section{References}

1. J.S. Dick, Rubber Technology : compounding and testing for performance (Hamser, 2001)

2. B.C. Barton, E.J. Hart, Rubber Chem Technol 26, 510-521(1953)

3. A. Coran, Rubber Chem Technol 37, 689-697 (1964)

4. A. Coran, Rubber Chem Technol 38, 1-14 (1965)

5. B. Poh, W. Tang, Journal of Applied Polymer Science 55, 537-542 (1995)

6. H. Ismail, P. Freakley, E. Sheng, Eur. Polym. J 31, 1049-1056 (1995)

7. H. Ismail, P. Freakley, I. Sutherland, E. Sheng, Eur. Polym. J 31, 1109-1117 (1995)

8. H. Ismail, H. Chia, Polym Test 17, 199-210 (1998)

9. H. Ismail, H. Chia, Eur. Polym. J 34, 1857-1863 (1998)

10. H. Ismail, U. Ishiaku, Z. Ishak, P. Freakley, Eur. Polym. J 33, 1-6 (1997)

11. I. Surya, H. Ismail, A. Azura, Polym Test 32, 13131321 (2013)

12. I. Surya, H. Ismail, A. Azura, Polym Test 40, 24 (2014).

13. I. Surya, H. Ismail, A. Azura, Polym Test 42, 208214 (2015)

14. I. Surya, H. Ismail, Plast Rubber and Compos 45, 287-293 (2016)

15. I. Surya, S. Fauzi Siregar, H. Ismail, E3S Web of Conferences 34, 01030 (2018)

16. P.J. Flory, J. Rehner Jr., J. Chem. Phys. 11, 521 (1943)

17. P.J. Flory, J. Chem. Phys. 18, 108-111 (1950)

18. H. Long, Basic Compounding and Processing of Rubber (Ohio, 1985)

19. I. Surya, H. Ismail, Polym Test 50, 276-282 (2016)

20. B. Boonstra, H. Cochrane, E. Dannenberg, Rubber Chem Technol 48, 558-576 (1975)

21. H. Cochrane, C. Lin, Rubber Chem Technol 66, 4860 (1993)

22. P. Teh, Z. Mohd Ishak, A. Hashim, J. KargerKocsis, U. Ishiaku, Eur. Polym. J 40, 2513-2521 (2004)

23. B. Boonstra, G. Taylor, Rubber Chem Technol 38, 943-960 (1965)

24. R. Nunes, J. Fonseca, M. Pereira, Polym Test 19, 93-103 (2000)
25. G. Kraus, Reinforcement of elastomers (John Wiley \& Sons Inc, 1965)

26. K. Polmanteer, C. Lentz, Rubber Chem Technol 48, 795-809 (1975)

27. D.L. Hertz Jr, Elastomerics 116, 17-21(1984) 